\title{
Salvianolic acid B improves autophagic dysfunction and decreases the apoptosis of cholesterol crystal-induced macrophages via inhibiting the Akt/mTOR signaling pathway
}

\author{
MENGQI SUN ${ }^{1 *}$, YUN YE $^{2 *}$, YILAN HUANG $^{2}$, WENXIAN YIN ${ }^{3}$, ZHAOLAN YU ${ }^{4}$ and SHURONG WANG ${ }^{2}$ \\ ${ }^{1}$ Drug Clinical Trial Institution; ${ }^{2}$ Department of Pharmacy, The Affiliated Hospital of \\ Southwest Medical University; ${ }^{3}$ Department of Pharmacy, The Affiliated Hospital of \\ Traditional Chinese Medicine Southwest Medical University; ${ }^{4}$ Department of Nephrology, \\ The Affiliated Hospital of Southwest Medical University, Luzhou, Sichuan 646000, P.R. China
}

Received September 17, 2020; Accepted May 7, 2021

DOI: $10.3892 / \mathrm{mmr} .2021 .12403$

\begin{abstract}
Progressive macrophage dysfunction and apoptosis are some of the major events that occur during atherogenesis. To further investigate the intrinsic association between atherosclerosis (AS) and macrophage apoptosis and autophagy, cholesterol crystals (CHCs) were used to stimulate RAW264.7 macrophages to establish a macrophage model of advanced AS. Cells in the CHC group were treated with salvianolic acid B (Sal B) to evaluate its protective effects and reveal its underlying molecular mechanism. The results demonstrated that treatments with Sal B significantly improved autophagy dysfunction and reduced the apoptotic rate of $\mathrm{CHC}$-induced macrophages. Furthermore, Sal B significantly attenuated $\mathrm{CHC}$-induced release of proinflammatory factors (TNF- $\alpha$ and IL-6) by macrophages. Treatment of macrophages with a specific inhibitor of autophagy (3-methyladenine) significantly reversed Sal B-mediated effects on autophagy, suggesting that Sal B-induced autophagy may display a protective effect in $\mathrm{CHC}$-induced macrophages. Furthermore, pretreatment of $\mathrm{CHC}$-induced macrophages with insulin significantly decreased Sal B-induced autophagy, indicating that the Akt/mTOR signaling pathway may serve as a critical mediator in regulating Sal B-mediated cell death. Taken together, the present study demonstrated that Sal B improved autophagic dysfunction and reduced the apoptosis of $\mathrm{CHC}$-induced macrophages via inhibiting the Akt/mTOR signaling pathway.
\end{abstract}

Correspondence to: Professor Shurong Wang, Department of Pharmacy, The Affiliated Hospital of Southwest Medical University, 25 Luzhou Taiping Street, Luzhou, Sichuan 646000, P.R. China

E-mail: lyfywsr@163.com

*Contributed equally

Key words: salvianolic acid B, atherosclerosis, RAW264.7 macrophages, autophagy, apoptosis

\section{Introduction}

According to the World Health Organization, among the 56.9 million deaths recorded worldwide in 2016, 15.2 million were caused by ischemic heart disease and stroke. Therefore, cardiovascular diseases have consistently ranked first in the list of global causes of death during the last 15 years (1). Atherosclerosis (AS) is an important foundation for these two diseases. The accumulation of foam cells and apoptotic residues, which are produced by foam cells, at the lesions are landmark events of both heart disease and stroke $(2,3)$. In the early stage of AS, macrophages reduce the lipids and apoptotic residues to limit plaque growth via endocytosis. During disease progression, the function of macrophages is decreased until it is lost, which is accompanied by increased cell apoptosis, eventually leading to necrosis, inflammation and plaque instability (4). The aforementioned findings suggested that reducing macrophage apoptosis and maintaining their normal function could be considered as a promising approach for the prevention and treatment of AS.

Autophagy is a cellular self-defense mechanism that has been widely studied in several organisms and is characterized by the intracellular degradation of organelles, proteins and other cytoplasmic components by lysosomes (5). When cells are exposed to external stimuli, such as oxidative stress and starvation, the lipid structure of the bilayer membrane encapsulates cytoplasmic substances, such as damaged organelles and misfolded proteins, to form autophagosomes. Subsequently, the autophagosome fuses with the lysosome to form an autophagolysosome, which in turn catabolizes cytoplasmic materials, including those internalized by endocytosis, through its acidic environment and proteases, thereby maintaining normal cell activity, morphology and structure, and delaying the aging process (6). Autophagy is also closely associated with the pathogenesis and prevention of malignant tumors, as well as cardiovascular, neurodegenerative and immune system diseases (7). For instance, it has been reported that macrophage autophagy exhibits an antiatherosclerotic effect via inhibiting inflammation and promoting cholesterol efflux $(8,9)$. 
Recently, an increasing number of researchers have turned their attention to the regulation of autophagy in apoptosis $(10,11)$. However, the intrinsic mechanisms underlying the association between autophagy and apoptosis have not yet been elucidated.

As a traditional Chinese medicine, Salvia miltiorrhiza is widely used in Asia for the prevention and treatment of cardiovascular diseases via promoting blood circulation (12). Salvianolic acid B (Sal B) is one of the main water-soluble components of Salvia miltiorrhiza (13). It has been reported that Sal B exerts anti-inflammatory, antioxidant and antitumor effects (12). In cardiovascular diseases, Sal B serves a significant role in protecting against myocardial infarction, improving myocardial ischemia-reperfusion injury and inhibiting the formation of atherosclerotic plaques (13-15). However, whether the antiatherosclerotic effects of Sal B are associated with macrophage apoptosis is not completely understood.

In the present study, RAW264.7 macrophages were treated with cholesterol crystals ( $\mathrm{CHCs}$ ) to investigate the intrinsic association between macrophage autophagy and apoptosis in AS. Furthermore, the mechanism underlying the protective effects of Sal B on macrophages in AS was explored.

\section{Materials and methods}

Cell culture. The RAW264.7 cell line was purchased from the American Type Culture Collection and cultured in high glucose DMEM (Gibco; Thermo Fisher Scientific, Inc.) supplemented with $10 \%(\mathrm{v} / \mathrm{v}) \mathrm{FBS}$ (Biological Industries) at $37^{\circ} \mathrm{C}$ in a $5 \%$ $\mathrm{CO}_{2}$ incubator.

Experimental design. In order to confirm whether $\mathrm{CHCs}$ can induce macrophage apoptosis and autophagy dysfunction, different concentrations of CHCs $(0,400,800,1,200 \mu \mathrm{g} / \mathrm{ml})$ were used to culture cells, followed by verification via Hoechst staining and western blotting. Next, different concentrations of Sal B (0, 40, 80, 120, 160, 200, 240, 280, 320, $360 \mu \mathrm{M})$ were used to culture cells and toxicity was evaluated via an MTT assay. A total of three different concentrations (100, $150,200 \mu \mathrm{M})$ were selected for subsequent experiments. Afterwards, cells were divided into five groups (untreated control; $800 \mu \mathrm{g} / \mathrm{ml} \mathrm{CHC;} 800 \mu \mathrm{g} / \mathrm{ml} \mathrm{CHC}+100 \mu \mathrm{M}$ Sal B; $800 \mu \mathrm{g} / \mathrm{ml} \mathrm{CHC}+150 \mu \mathrm{M} \mathrm{Sal} \mathrm{B}$; and $800 \mu \mathrm{g} / \mathrm{ml} \mathrm{CHC}+200 \mu \mathrm{M}$ Sal B) and then it was evaluated whether Sal B could prevent CHC-induced apoptosis, autophagy and inflammation via Hoechst, flow cytometry, western blotting and ELISA. In addition, the effect of Sal B on the autophagic flow of CHC-treated cells was detected via an Ad-GFP-LC3B adenovirus infection experiment [experimental groups were as follows: Untreated control; $800 \mu \mathrm{g} / \mathrm{ml} \mathrm{CHC;} 800 \mu \mathrm{g} / \mathrm{ml} \mathrm{CHC}+200 \mu \mathrm{M}$ Sal B; $20 \mathrm{nM}$ BafA1 $+800 \mu \mathrm{g} / \mathrm{ml} \mathrm{CHC}+200 \mu \mathrm{M}$ Sal B; and $20 \mathrm{nM}$ bafilomycin A1 (BafA1; Beijing Huamaike Biotechnology Co., Ltd.)]. Following which, cells were divided into four groups [experimental groups were as follows: Untreated control; $800 \mu \mathrm{g} / \mathrm{ml} \mathrm{CHC;} 800 \mu \mathrm{g} / \mathrm{ml} \mathrm{CHC}+200 \mu \mathrm{M}$ Sal B; and $800 \mu \mathrm{g} / \mathrm{ml} \mathrm{CHC}+200 \mu \mathrm{M}$ Sal B $+5 \mathrm{mM} 3$-methyladenine (3-MA; Selleck Chemicals)] and the relationship between the reduction in apoptosis and the improvement of autophagy mediated by Sal B was explored via western blotting and flow cytometry. Ultimately, cells were divided into four groups [experimental groups were as follows: Untreated control; $800 \mu \mathrm{g} / \mathrm{ml} \mathrm{CHC} ; 800 \mu \mathrm{g} / \mathrm{ml} \mathrm{CHC}+200 \mu \mathrm{M}$ Sal B; and $800 \mu \mathrm{g} / \mathrm{ml} \mathrm{CHC}+200 \mu \mathrm{M} \mathrm{Sal} \mathrm{B}+1 \mu \mathrm{g} / \mathrm{ml}$ insulin (Beyotime Institute of Biotechnology)] and the signaling pathway of Sal B-induced autophagy was evaluated via western blotting. After each intervention drug was added, cells were cultured at $37^{\circ} \mathrm{C}$ for $24 \mathrm{~h}$ before further experiments.

Preparation of CHCs. Cholesterol powder (Beyotime Institute of Biotechnology) was diluted in $95 \%$ ethanol to a final concentration of $12.5 \mathrm{mg} / \mathrm{ml}$ and then heated to $65^{\circ} \mathrm{C}$. Once sufficiently dissolved, the cholesterol solution was filtered through filter paper to remove undissolved impurities. Subsequently, the solution was cooled in an ice bath to precipitate crystals and then filtered through filter paper to obtain crystals. The aforementioned steps were repeated five times. Subsequently, all crystals were collected, grounded using a mortar, dispersed in PBS, adjusted to a final concentration of $5 \mathrm{mg} / \mathrm{ml}$ and stored at $-20^{\circ} \mathrm{C}$ following autoclaving.

Cell viability assay. RAW264.7 cells (5x104/well) were seeded into 96 -well plates and treated with different concentrations of Sal B for $24 \mathrm{~h}$. Then, the activity of cells was evaluated using an MTT assay. Subsequently, each well was supplemented with $5 \mu \mathrm{l}$ MTT solution ( $5 \mathrm{mg} / \mathrm{ml}$; Beyotime Biotechnology). Following incubation for $3 \mathrm{~h}$, the medium was discarded and $150 \mu \mathrm{l}$ DMSO (Sangon Biotech Co., Ltd.) was added to each well to dissolve the formed crystals. Finally, the optical density of each well was measured using a microplate reader (Molecular Devices, LLC) at a wavelength of $490 \mathrm{~nm}$.

Cell apoptosis analysis. Following treatment with the corresponding treatments for $24 \mathrm{~h}$, RAW264.7 cell apoptosis was evaluated by performing Hoechst staining. Briefly, cells (40) $10^{4}$ cells/well) were seeded into 6-well plates and cultured for $24 \mathrm{~h}$, then the medium was discarded. After washing with PBS, cells were fixed with $4 \%$ paraformaldehyde $(500 \mu \mathrm{l} /$ well; Boster Biological Technology) for $15 \mathrm{~min}$ at $4^{\circ} \mathrm{C}$. Cells were washed again with PBS and then stained with $500 \mu \mathrm{l}$ Hoechst 33258 (Beyotime Institute of Biotechnology) for $10 \mathrm{~min}$ at room temperature in the dark. Finally, after washing with PBS, morphological changes were observed under a fluorescence microscope (Thermo Fisher Scientific, Inc.).

In addition, RAW264.7 cells $\left(50 \times 10^{4}\right.$ cells/well) were seeded into 6-well plates and treated with $\mathrm{CHCs}$ for $24 \mathrm{~h}$. Then, the apoptosis rate was detected by conducting Annexin V-FITC/PI double staining. Briefly, the medium was aspirated, and cells were washed with $\mathrm{PBS}$, digested with trypsin (Beyotime Institute of Biotechnology), collected into a centrifuge tube and centrifuged at $400 \mathrm{x} \mathrm{g}$ for $4 \mathrm{~min}$ at $4^{\circ} \mathrm{C}$. Cells $\left(1 \times 10^{6}\right.$ cells $\left./ \mathrm{ml}\right)$ were resuspended in $1 \mathrm{X}$ Binding Buffer (BD Biosciences). Subsequently, $100 \mu \mathrm{l}$ cell suspension was supplemented with $5 \mu \mathrm{l}$ Annexin V-FITC and $5 \mu \mathrm{l}$ PI (both from BD Biosciences). Following staining for $15 \mathrm{~min}$ at room temperature in the dark, $400 \mu \mathrm{l} 1 \mathrm{X}$ Binding Buffer was added and the apoptotic rate was measured within $30 \mathrm{~min}$ via flow cytometric analysis (BD FACSymphony ${ }^{\mathrm{TM}}$ S6; Becton, Dickinson and Company). FlowJo software version 10.5.3 (FlowJo LLC) was used for analysis. 
Detection of the inflammatory factors $T N F-\alpha$ and $I L-6$. Following treatment with the corresponding intervention drugs for $24 \mathrm{~h}$, the levels of the inflammatory factors TNF- $\alpha$ and IL-6 were measured by performing ELISAs. Cells were centrifuged at $400 \mathrm{x} \mathrm{g}$ for $20 \mathrm{~min}$ at $4^{\circ} \mathrm{C}$. Subsequently, the levels of TNF- $\alpha$ (cat. no. JM-02415M2) and IL-6 (cat. no. JM-02446M1) in the supernatant were measured using the appropriate ELISA kits (Jingmei Biotechnology) according to the manufacturer's instructions.

Cell transfection with Ad-GFP-LC3B adenovirus. To assess autophagy, RAW264.7 cells were infected with Ad-GFP-LC3B adenovirus (cat. no. C3006; Beyotime Institute of Biotechnology). The cells were inoculated into 12-well plates, then the culture medium was changed and an appropriate volume of virus solution was added $24 \mathrm{~h}$ later (MOI 20). After culturing at $37^{\circ} \mathrm{C}$ for $24 \mathrm{~h}$, cells were treated with the corresponding intervention drugs for $24 \mathrm{~h}$. Cell proliferation and the expression of fluorescent protein were observed under a fluorescence microscope.

Western blotting. Following treatment of RAW264.7 cells with the corresponding intervention drugs, the protein expression levels of cleaved-caspase 3 (1:500; cat. no. ab2302; Abcam), pro-caspase 3 (1:1,000; cat. no. ab32150; Abcam), Bax (1:2,000; cat. no. ab182733; Abcam), Bcl-2 (1:2,000; cat. no. ab182858; Abcam), LC3-II (1:2,000; cat. no. ab192890; Abcam), beclin-1, p62 (1:10,000; cat. no. ab109012; Abcam), p-mTOR (1:1,000; cat. no. 5536; Cell Signaling Technology, Inc.), mTOR (1:1,000; cat. no. 2972; Cell Signaling Technology, Inc.), p-Akt (1:1,000; cat. no. 13038; Cell Signaling Technology, Inc.) and Akt (1:1,000; cat. no. 9272; Cell Signaling Technology, Inc.) were determined by performing western blotting. Briefly, the cells were seeded into 6-well plates at $40 \times 10^{4}$ cells/well. After $24 \mathrm{~h}$, intervention drugs were added and cells were incubated for another $24 \mathrm{~h}$. Afterwards, total protein was extracted from cells using lysis buffer consisting of RIPA lysate (Beyotime Institute of Biotechnology), 5X protease inhibitor reagent (Roche Diagnostics) and 1\% phenylmethylsulfonyl fluoride (Beyotime Institute of Biotechnology) for $30 \mathrm{~min}$ on ice. Subsequently, cells were centrifuged $\left(400 \times \mathrm{g}, 4^{\circ} \mathrm{C}, 20 \mathrm{~min}\right)$ to obtain the supernatant, the protein concentration was measured using a BCA protein quantification kit (Beyotime Institute of Biotechnology) and then the proteins were denatured. Proteins $(10 \mu \mathrm{g})$ were separated via SDS-PAGE $(15 \%$ gel for LC3 and 12\% gel for other proteins) and transferred onto a PVDF membrane (EMD Millipore). Following blocking with $5 \%$ skimmed milk powder at room temperature for $1 \mathrm{~h}$, the membrane was incubated with the aforementioned primary antibodies for $24 \mathrm{~h}$ at $4^{\circ} \mathrm{C}$. Subsequently, the membrane was incubated with corresponding secondary antibodies (Goat anti-Rabbit; 1:10,000; cat. no. bs-0295Gs; BIOSS) for $1 \mathrm{~h}$ at room temperature. Following washing with TBST (0.1\% Tween-20; Beijing Solarbio Science \& Technology Co., Ltd.), protein bands were visualized using an ECL developing solution (EMD Millipore) and evaluated using a Bio-Rad gel imaging system (Bio-Rad Laboratories, Inc.). $\beta$-actin (1:5,000; cat. no. bs-0061R; BIOSS) was used as the loading control. ImageJ (v1.52; National Institutes of Health) was used for semi-quantification.
Statistical analysis. Experiments were repeated in triplicate. Statistical analyses were performed using SPSS 17.0 (SPSS, Inc.), GraphPad Prism 8.0.2 (GraphPad Software, Inc.) software. Data are presented as the mean $\pm \mathrm{SD}$. Comparisons among multiple groups were analyzed using one-way ANOVA followed by Tukey's post hoc test. $\mathrm{P}<0.05$ was considered to indicate a statistically significant difference.

\section{Results}

Treatment with CHCs induces apoptosis and autophagic dysfunction in RAW264.7 macrophages. To investigate whether CHCs could induce macrophage apoptosis, Hoechst 33258 staining assays were conducted to observe the morphological alterations of cell nuclei. Following treatment of RAW264.7 cells with different concentrations of CHCs for $24 \mathrm{~h}$, apoptosis-related morphological changes were markedly increased in the cell nuclei, including chromatin condensation and nuclear fragmentation, compared with the control group (Fig. 1A). Subsequently, western blotting was performed to evaluate the effect of CHCs on the expression of key apoptotic factors. The results revealed that, compared with the untreated control group, the ratios of cleaved-caspase 3/pro-caspase 3 and $\mathrm{Bax} / \mathrm{Bcl}-2$ were significantly increased in CHC-treated (800 and 1,200 $\mu \mathrm{g} / \mathrm{ml}$ ) RAW264.7 macrophages (Fig. 1B).

Furthermore, to determine whether CHCs could induce autophagic dysfunction in RAW264.7 macrophages, their effect on the expression of autophagy-related proteins was evaluated. The expression levels of LC3-II and beclin-1 were significantly downregulated, whereas that of p62 was significantly upregulated in CHC-induced RAW264.7 cells at doses of 800 and $1,200 \mu \mathrm{g} / \mathrm{ml}$ compared with those in the untreated control group (Fig. 1C). The aforementioned findings suggested that $\mathrm{CHCs}(800 \mu \mathrm{g} / \mathrm{ml})$ promoted apoptosis and autophagic dysfunction in RAW264.7 macrophages.

Sal B reduces $C H C$-induced apoptosis and the expression of proinflammatory cytokines in RAW264.7 macrophages. To evaluate the toxicity of Sal B, an MTT viability assay was performed. Following treatment of RAW264.7 macrophages with different concentrations of Sal B for $24 \mathrm{~h}$, the MTT assay results revealed that Sal B ( $>240 \mu \mathrm{M})$ significantly attenuated the viability of macrophages compared with the untreated control group (Fig. 2A). Therefore, the concentrations of 100,150 and $200 \mu \mathrm{M}$ Sal B were selected for subsequent experiments. The western blotting results demonstrated that the expression levels of autophagy-related proteins were significantly altered by Sal B treatment at the aforementioned concentrations compared with those in the untreated control group (Fig. 2B).

In addition, the effect of Sal B on CHC-induced apoptosis in RAW264.7 macrophages was evaluated using Hoechst 33258 staining. Treatment of RAW264.7 macrophages with Sal B notably reduced CHC-induced nuclear apoptosis-related morphological changes in cell nuclei (Fig. 3A). Additionally, the western blotting results demonstrated that, compared with the CHC group, the cleaved-caspase 3/pro-caspase 3 and $\mathrm{Bax} / \mathrm{Bcl}-2$ ratios were significantly decreased in $\mathrm{CHC}$-induced cells treated with Sal B for $24 \mathrm{~h}$ (Fig. 3B). 

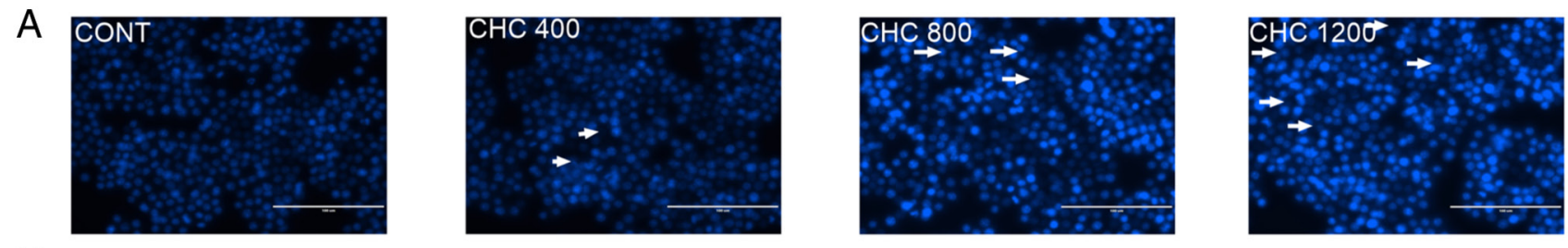

B

$\mathrm{CHC}(\mu \mathrm{g} / \mathrm{ml}) \quad 0 \quad 4008001200$
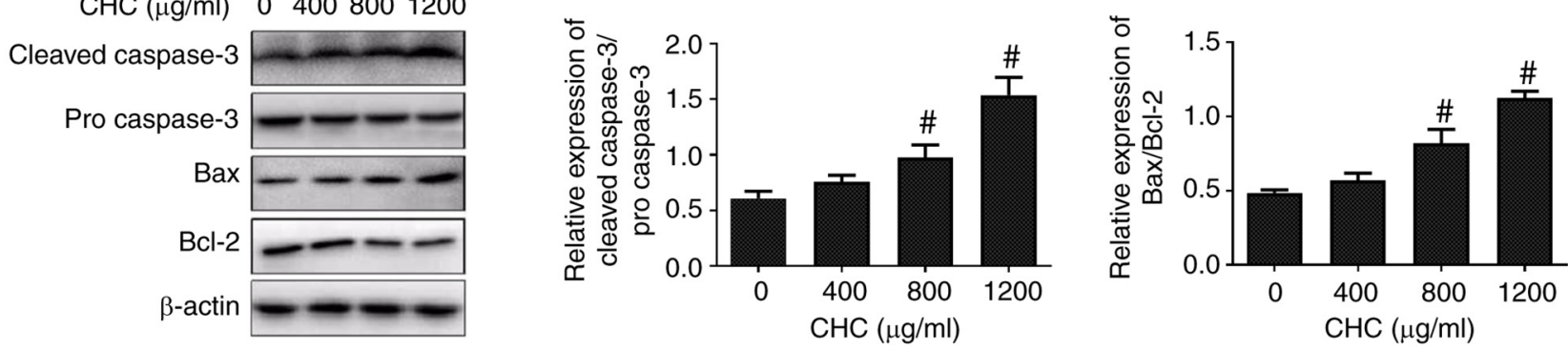

C
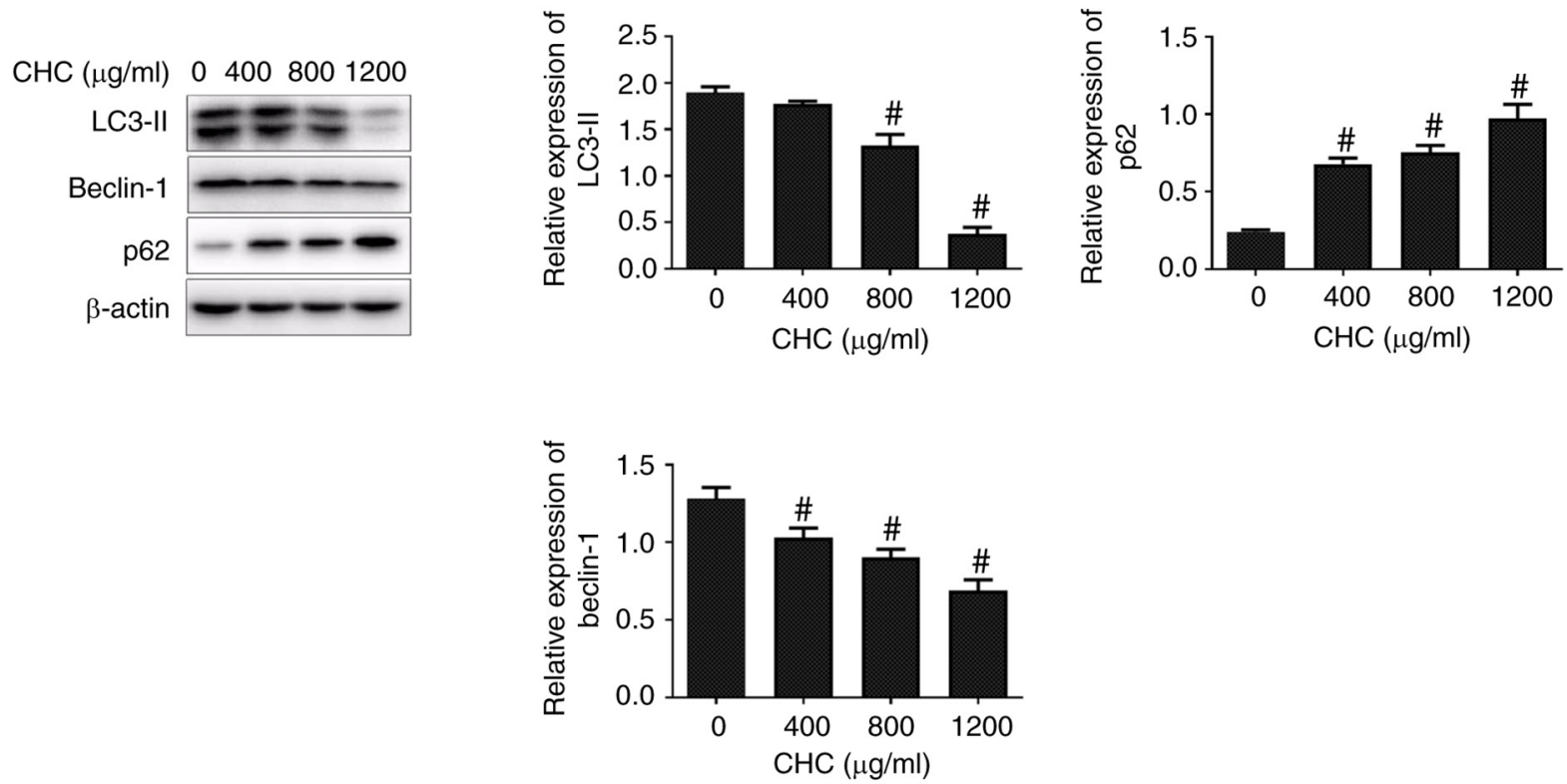

Figure 1. Treatment with CHCs induces RAW264.7 macrophage apoptosis and autophagic dysfunction. The following groups are presented: CONT, untreated control; CHC 400, $400 \mu \mathrm{g} / \mathrm{ml} \mathrm{CHC;} \mathrm{CHC} \mathrm{800,} 800 \mu \mathrm{g} / \mathrm{ml} \mathrm{CHC}$; and CHC 1,200, 1,200 $\mu \mathrm{g} / \mathrm{ml} \mathrm{CHC.} \mathrm{(A)} \mathrm{Morphological} \mathrm{features} \mathrm{of} \mathrm{CHC-induced} \mathrm{apop-}$ tosis in RAW264.7 cells were evaluated by performing Hoechst 33258 staining. White arrows indicate apoptotic cells (scale bar, $100 \mu \mathrm{m}$ ). Western blotting was performed to determine the expression levels of (B) apoptosis- and (C) autophagy-related proteins in CHC-induced RAW264.7 macrophages ( $\mathrm{n}=3$ ). ${ }^{\text {" }} \mathrm{P}<0.05$ vs. CONT. CHC, cholesterol crystal.

To acquire quantification of cell apoptosis, an Annexin V-FITC/PI dual staining assay was performed. As shown in Fig. 3C, the apoptotic rate in the untreated control group was $7.76 \pm 0.38 \%$. Compared with the untreated control group, the apoptotic rate in CHC-induced cells was significantly increased $(26.42 \pm 0.59 \%)$. Additionally, treatment of CHC-induced RAW264.7 macrophages with 100,150 and $200 \mu \mathrm{M}$ Sal B significantly decreased the apoptotic rate to $23.20 \pm 0.71$, $18.95 \pm 1.13$ and $13.33 \pm 0.51 \%$, respectively, compared with cells treated $\mathrm{CHC}$ alone. Furthermore, the secretion levels of proinflammatory cytokines (TNF- $\alpha$ and IL-6) were significantly reduced in Sal B-treated, CHC-induced RAW264.7 macrophages compared with those in the CHC + LPS group (Fig. 3D). These results indicated that Sal B attenuated CHC-induced RAW264.7 macrophage apoptosis and the production of proinflammatory cytokines.
Sal B improves CHC-induced autophagic dysfunction in RAW264.7 macrophages. To assess whether Sal B could ameliorate CHC-induced autophagy dysfunction in RAW264.7 macrophages, western blotting was performed to detect the expression levels of autophagy-related proteins. Compared with the $\mathrm{CHC}$ group, the results demonstrated that the expression levels of LC3-II and beclin-1 were significantly increased, whereas those of $\mathrm{p} 62$ were significantly decreased in RAW264.7 macrophages co-treated with Sal B and CHCs for $24 \mathrm{~h}$ (Fig. 4A).

In addition, to further verify the Sal B-mediated autophagic flux, RAW264.7 macrophages were infected with Ad-GFP-LC3B for $24 \mathrm{~h}$. Following cell treatment with BafA1, an autophagosome-lysosome degradation inhibitor, the specific green fluorescent point distribution of LC3B was observed under a microscope. As shown in Fig. 4B, a 
A

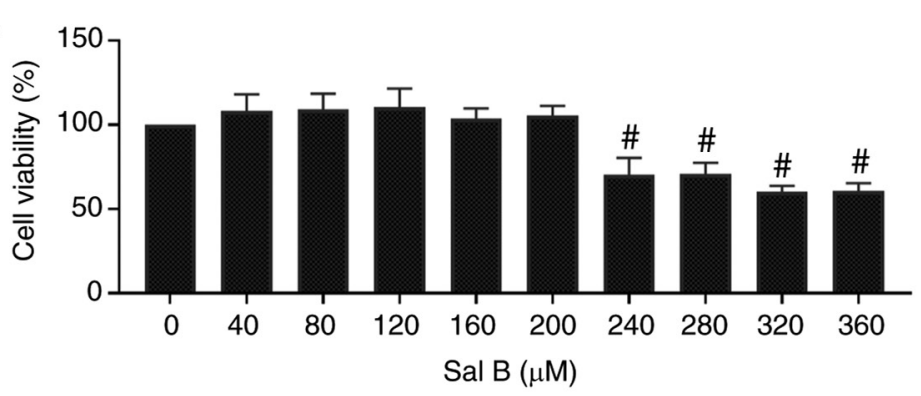

B
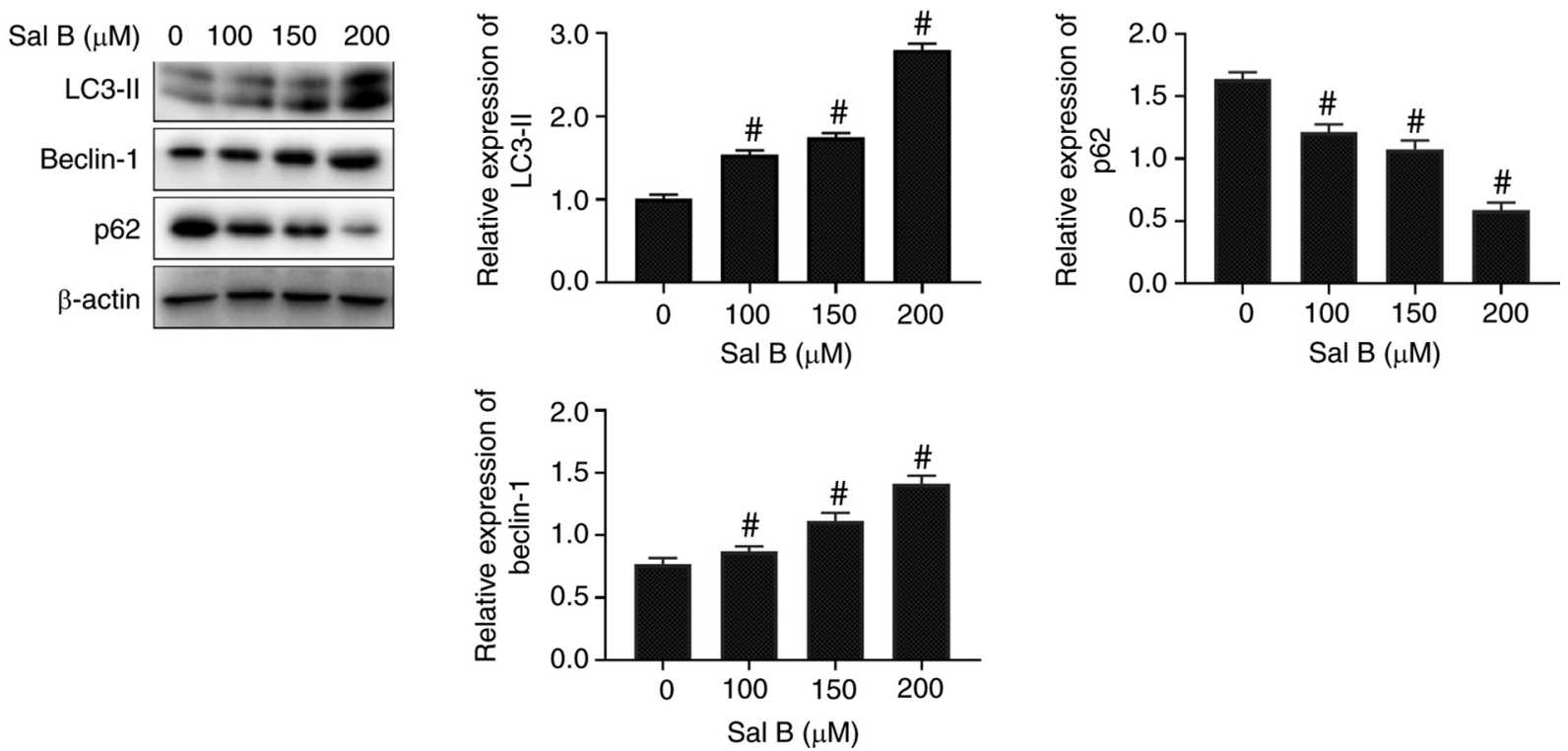

Figure 2. Sal B activates autophagy in RAW264.7 macrophages. (A) Effect of Sal B on RAW264.7 macrophage viability (n=6). The following groups are presented: Sal B 0, 40, 80, 120, 160,200,240,280,320,360 $\mu \mathrm{M}$. (B) Western blotting was performed to determine the expression levels of the autophagy-related proteins in Sal B-induced RAW264.7 macrophages $(\mathrm{n}=3)$. The following groups are presented: Sal B 0, 100, $150,200 \mu \mathrm{M} .{ }^{\#} \mathrm{P}<0.05$ vs. untreated control. Sal B, salvianolic acid B.

markedly enhanced accumulation of green fluorescent puncta was observed in CHC-induced and Sal B-treated RAW264.7 macrophages treated with $20 \mathrm{nM}$ BafA1 for $4 \mathrm{~h}$ compared with the $\mathrm{CHC}+\mathrm{Sal} \mathrm{B}$ group. These findings suggested that Sal B improved CHC-induced autophagic dysfunction in RAW264.7 macrophages.

Sal B attenuates CHC-induced RAW264.7 macrophage apoptosis partially via improving autophagic dysfunction. The inhibitor 3-MA is widely used to selectively inhibit the activity of type III PI3K, thereby blocking the formation of autophagosomes (16). To further explore the association between Sal B-mediated decreases in apoptosis and improvements in autophagy, RAW264.7 macrophages were co-treated with Sal B and 3-MA for 24 h. Subsequently, western blotting was performed to detect alterations in the expression levels of autophagy- and apoptosis-related proteins. As shown in Fig. 5A, compared with the Sal B + CHC group, LC3-II and beclin-1 expression levels were significantly downregulated, but p62 was significantly upregulated in CHC-induced RAW264.7 macrophages co-treated with Sal B and 3-MA.

More importantly, 3-MA-mediated autophagy inhibition significantly increased the cleaved caspase 3/pro-caspase 3 and Bax/Bcl-2 ratios in Sal B-treated CHC-induced RAW264.7 macrophages (Fig. 5B). Consistent with the western blotting results, the Annexin V-FITC/PI dual staining assay results revealed that the apoptotic rate of RAW264.7 macrophages treated with Sal B and 3-MA was also significantly enhanced compared with that in the Sal B + CHC group (Fig. 5C). Overall, the aforementioned results indicated that Sal B attenuated CHC-induced apoptosis in RAW264.7 macrophages partially via improving autophagic dysfunction.

Sal B improves CHC-induced autophagic dysfunction in RAW264.7 macrophages partially via inhibiting the Akt/mTOR signaling pathway. The Akt/mTOR signaling pathway serves an important role in the regulation of autophagy (17). Therefore, the present study aimed to investigate whether the Akt/mTOR signaling pathway was involved in Sal B-induced autophagy. The western blotting results demonstrated that, compared with the untreated control group, the $\mathrm{p}$-mTOR/mTOR and p-Akt/Akt ratios were significantly elevated in the $\mathrm{CHC}$ group (Fig. 6A). However, the p-mTOR/mTOR and p-Akt/Akt ratios were significantly decreased in the Sal B groups compared with the $\mathrm{CHC}$ group. These findings revealed that Sal B exerted an effective inhibitory effect on the Akt/mTOR signaling pathway, thus improving $\mathrm{CHC}$-induced autophagy dysfunction in RAW264.7 macrophages.

Subsequently, RAW264.7 macrophages were co-treated with Sal B and insulin, an activator of the PI3K/Akt/mTOR 
A

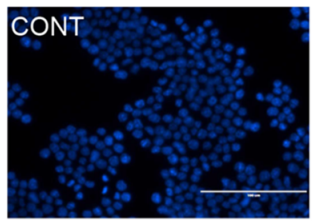

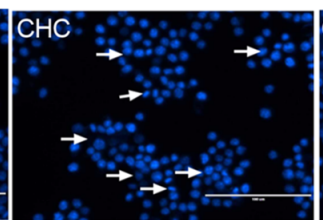
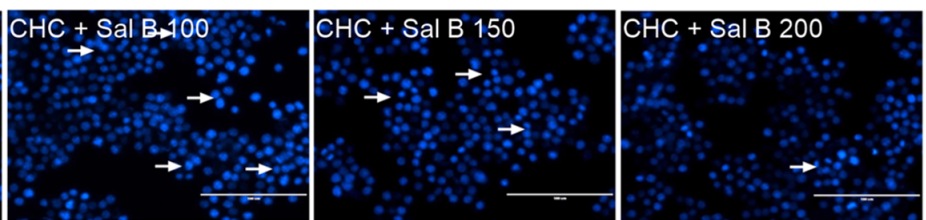

B

Sal B $(\mu \mathrm{M})--100150200$ $\mathrm{CHC}(800 \mu \mathrm{g} / \mathrm{ml})-++++$

Cleaved caspase- 3

Pro caspase- 3
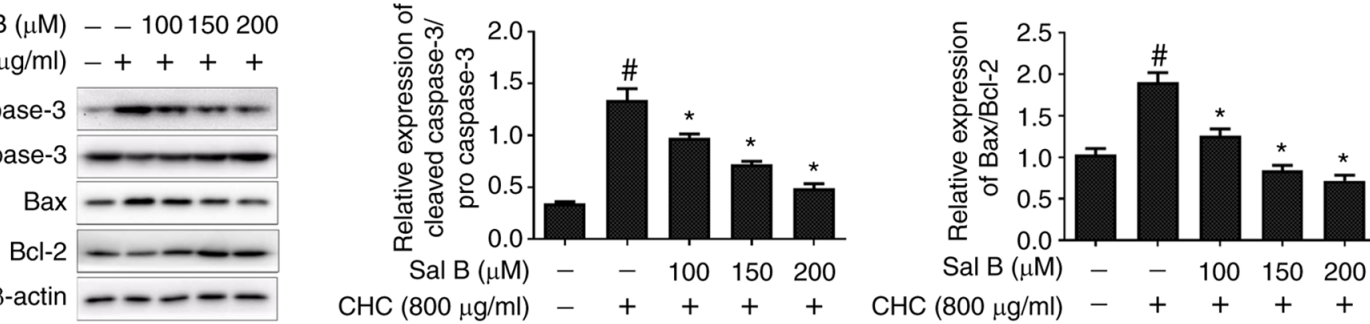

C

CONT
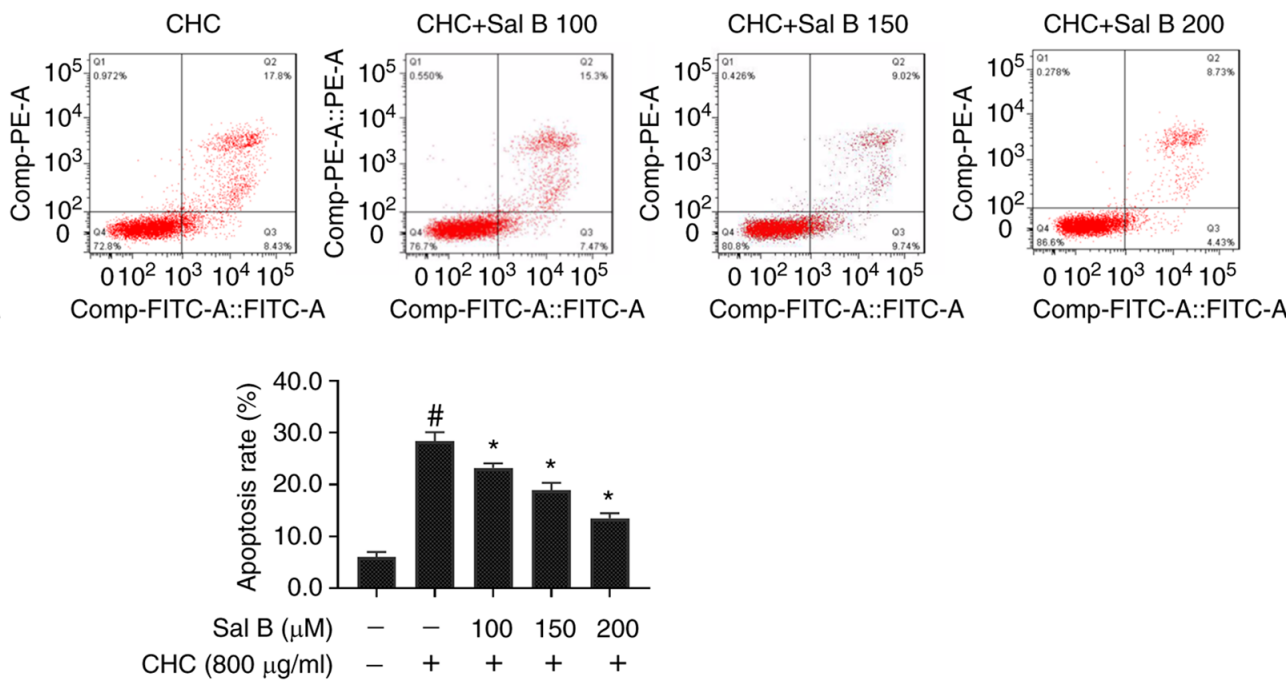

D

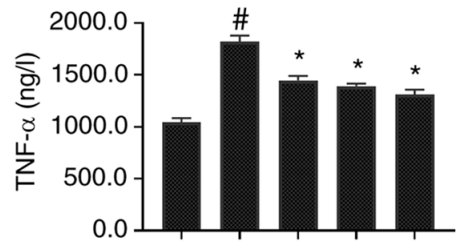

Sal B $(\mu \mathrm{M}) \quad-\quad-\quad 100150200$

$\mathrm{CHC}(800 \mu \mathrm{g} / \mathrm{ml})-++++$

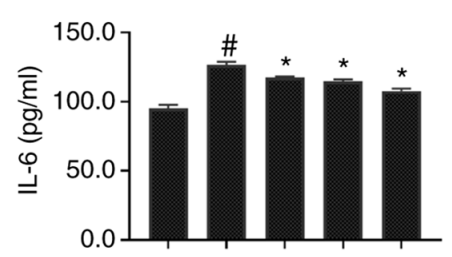

Sal B $(\mu \mathrm{M}) \quad-\quad-100150200$

$\mu++++$

Figure 3. Sal B attenuates CHC-induced apoptosis and the secretion of proinflammatory cytokines in RAW264.7 macrophages. The following groups are presented: CONT, untreated control; CHC, $800 \mu \mathrm{g} / \mathrm{ml} \mathrm{CHC;} \mathrm{CHC} \mathrm{+} \mathrm{Sal} \mathrm{B} \mathrm{100,} 800 \mu \mathrm{g} / \mathrm{ml} \mathrm{CHC}+100 \mu \mathrm{M} \mathrm{Sal} \mathrm{B} ; \mathrm{CHC}+\mathrm{Sal} \mathrm{B} 150,800 \mu \mathrm{g} / \mathrm{ml} \mathrm{CHC}+150 \mu \mathrm{M}$ Sal B; and CHC + Sal B 200, $800 \mu \mathrm{g} / \mathrm{ml} \mathrm{CHC}+200 \mu \mathrm{M}$ Sal B. (A) Morphological features of CHC-induced and Sal B-treated RAW264.7 cells were evaluated by performing Hoechst 33258 staining. White arrows indicate apoptotic cells (scale bar, $100 \mu \mathrm{m}$ ). (B) Western blotting was performed to determine the expression levels of apoptosis-related proteins in CHC-induced RAW264.7 macrophages following treatment with Sal B ( $\mathrm{n}=3$ ). ${ }^{\text {}} \mathrm{P}<0.05$ vs. untreated control group; ${ }^{*} \mathrm{P}<0.05$ vs. CHC group. (C) Annexin V-FITC/PI double staining was performed to assess the effect of Sal B on the apoptotic rate of CHC-induced RAW264.7 macrophages (n=3). (D) ELISAs were performed to assess the effect of Sal B on the release of TNF- $\alpha$ and IL-6 by CHC-induced RAW264.7 macrophages $(\mathrm{n}=3) .{ }^{\#} \mathrm{P}<0.05$ vs. untreated control; ${ }^{*} \mathrm{P}<0.05$ vs. CHC. Sal B, salvianolic acid B; CHC, cholesterol crystal.

signaling pathway, for $24 \mathrm{~h}$. As shown in Fig. 6B, compared with the Sal B + CHC group, the p-mTOR/mTOR and p-Akt/Akt ratios were significantly increased in Sal B + insulin-treated RAW264.7 macrophages, whereas the expression levels of LC3-II and beclin-1 were significantly downregulated. In conclusion, these findings revealed that insulin partially restored Sal B-induced autophagy via activating the Akt/mTOR signaling pathway, which suggested that Sal $\mathrm{B}$ partially inhibited the Akt/mTOR signaling pathway to improve CHC-induced autophagy dysfunction in RAW264.7 macrophages.

\section{Discussion}

The role of apoptosis in the pathological process of AS has received increasing attention. Several factors further promote macrophage inflammatory responses and apoptosis, secondary inflammation and necrosis of other cells at the site 


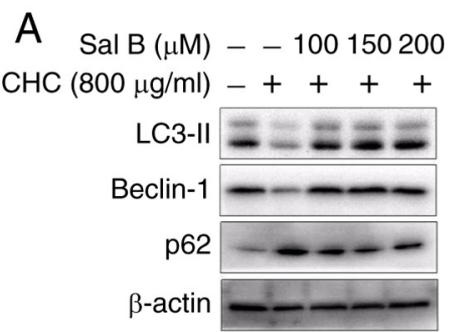

B

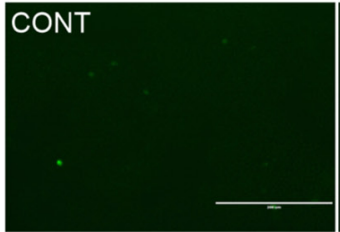

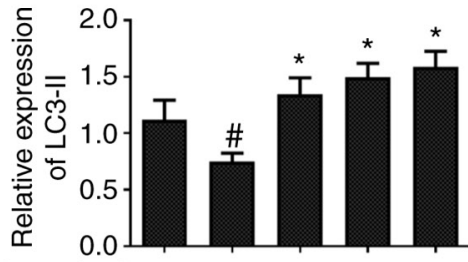

Sal B $(\mu \mathrm{M}) \quad-\quad-\quad 100150200$ $\mathrm{CHC}(800 \mu \mathrm{g} / \mathrm{ml})-++++$

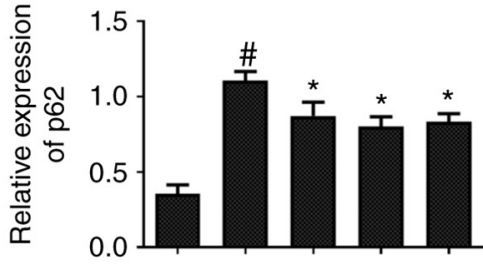

Sal B $(\mu \mathrm{M}) \quad-\quad$ - 100150200

$\mathrm{CHC}(800 \mu \mathrm{g} / \mathrm{ml})-+\quad+\quad+\quad+$

Figure 4. Sal B improves CHC-induced autophagic dysfunction in RAW264.7 macrophages. The following groups are presented: CONT, untreated control; $\mathrm{CHC}, 800 \mu \mathrm{g} / \mathrm{ml} \mathrm{CHC} ; \mathrm{CHC}+\mathrm{Sal} \mathrm{B}, 800 \mu \mathrm{g} / \mathrm{ml} \mathrm{CHC}+200 \mu \mathrm{M}$ Sal B; BafA1 + CHC + Sal B, $20 \mathrm{nM} \mathrm{BafA} 1+800 \mu \mathrm{g} / \mathrm{ml} \mathrm{CHC}+200 \mu \mathrm{M} \mathrm{Sal} \mathrm{B} ;$ and BafA1, $20 \mathrm{nM}$ BafA1. (A) Western blotting was performed to detect the expression of autophagy-related proteins in RAW264.7 macrophages treated with Sal B and CHCs for $24 \mathrm{~h}(\mathrm{n}=3)$. (B) Fluorescence microscopy was performed to assess GFP-LC3 autophagic spots in RAW264.7 macrophages treated with Sal B and CHCs for $24 \mathrm{~h}$ (scale bar, $200 \mu \mathrm{m}$ ). ${ }^{\#} \mathrm{P}<0.05$ vs. untreated control; ${ }^{*} \mathrm{P}<0.05$ vs. CHC. Sal B, salvianolic acid B; CHC, cholesterol crystals; BafA1, bafilomycin A1 inhibitor.

of the plaque, thereby leading to increased plaque instability, and eventually thrombosis (18-20). Therefore, reducing apoptosis and maintaining normal endocytic capacity in macrophages could be considered as a potential therapeutic approach for advanced AS. CHCs are commonly found in the necrotic core and atherosclerotic subendothelium (21). Emerging evidence has suggested that the massive accumulation of $\mathrm{CHCs}$ at the lesions induces inflammatory responses and increases plaque instability (22-25). Sergin et al (26) demonstrated that $\mathrm{CHCs}$ could increase the expression of p62 and ubiquitinated proteins at the site of the lesion. However, whether CHCs can promote macrophage apoptosis in atherosclerotic lesions and their specific underlying mechanism remains to be elucidated. The present study revealed that $\mathrm{CHCs}$ induced macrophage apoptosis and autophagy dysfunction.

As a highly conserved and widespread physiological and defense mechanism in organisms (27), the effects of autophagy on the development of several diseases have been the focus of research. Liao et al (8) suggested that macrophage-mediated autophagy displayed an inhibitory effect on the progression of AS. In addition, the role of traditional Chinese medicine in provoking and suppressing autophagy for treating different diseases has also received increasing attention. In traditional Chinese medicine, Salvia miltiorrhiza has been widely used in the treatment of cardiovascular diseases by relieving pain and promoting blood circulation (28).
Sal B, one of the primary water-soluble components in the Salvia miltiorrhiza extracts, also exerts protective effects against various cardiovascular diseases (29-31). However, no study has yet investigated the possible benefits of Sal B in $\mathrm{CHC}$-induced apoptosis. The present study showed that Sal B offered an important protective effect to alleviate macrophage autophagy dysfunction and apoptosis in advanced AS. The protective effects of Sal B were determined in the current study via the Hoechst 33258 staining assay, as demonstrated by the reduction in the apoptosis of $\mathrm{CHC}$-insulted macrophages and the decreased Annexin V-FITC/PI staining. The western blotting results indicated that Sal B significantly increased autophagy in CHC-induced macrophages, which was consistent with the results obtained by Jing et al (32). Surprisingly, the ELISA results also demonstrated that Sal B significantly attenuated the release of proinflammatory cytokines (TNF- $\alpha$ and IL-6) by CHC-induced macrophages, and we hypothesized that the aforementioned mechanism was closely associated with Sal B-mediated improvements in macrophage autophagy. However, the specific mechanism requires further investigation.

It has been suggested that autophagy is an upstream response to apoptosis, indicating that apoptosis is mediated by the activation of autophagy (33-35). However, it has also been suggested that enhancing autophagy may attenuate apoptosis (36). For example, Wang et al (37) demonstrated that apigenin could simultaneously induce autophagy and 

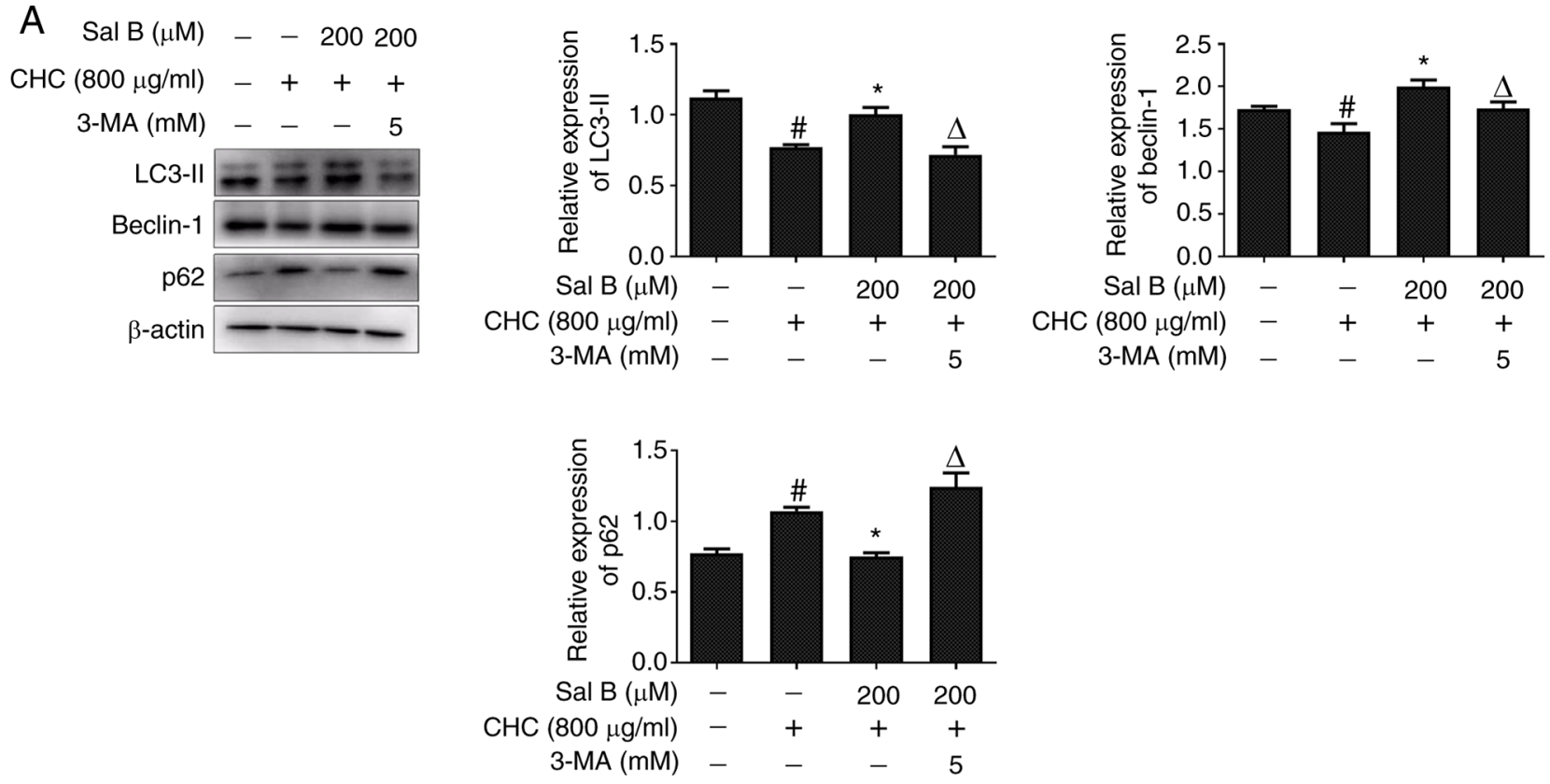

\section{B

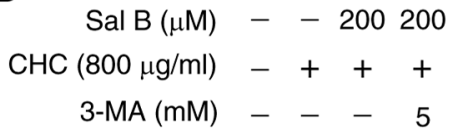
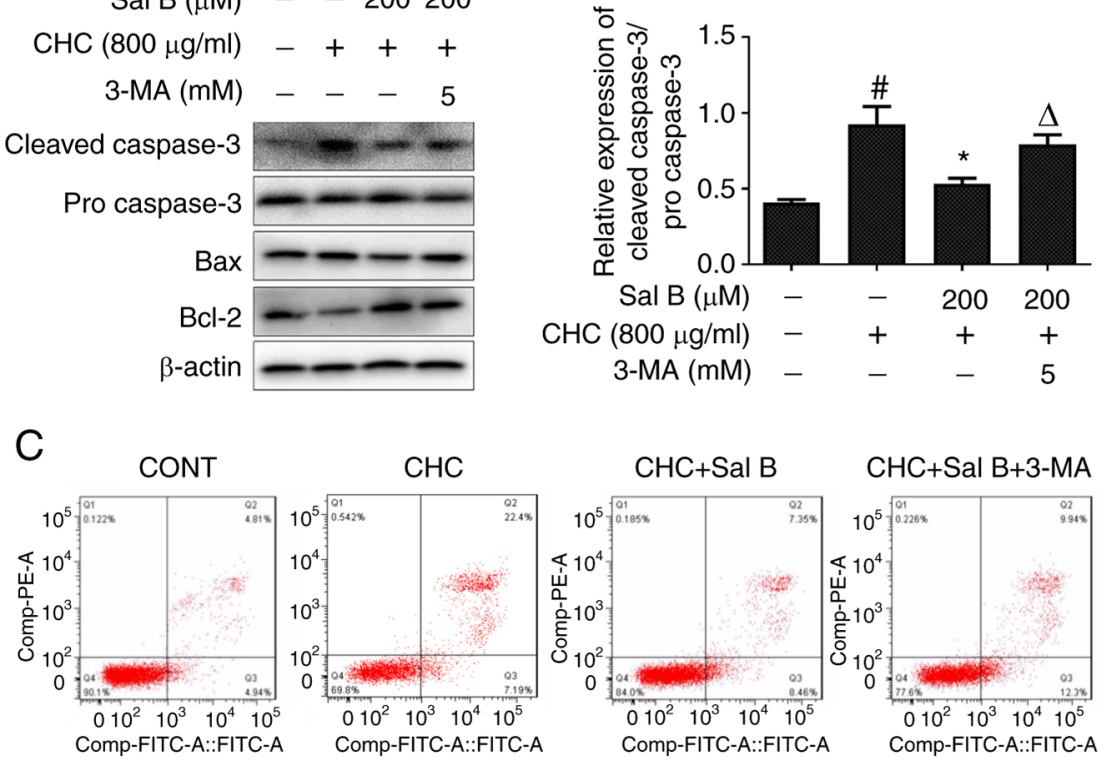
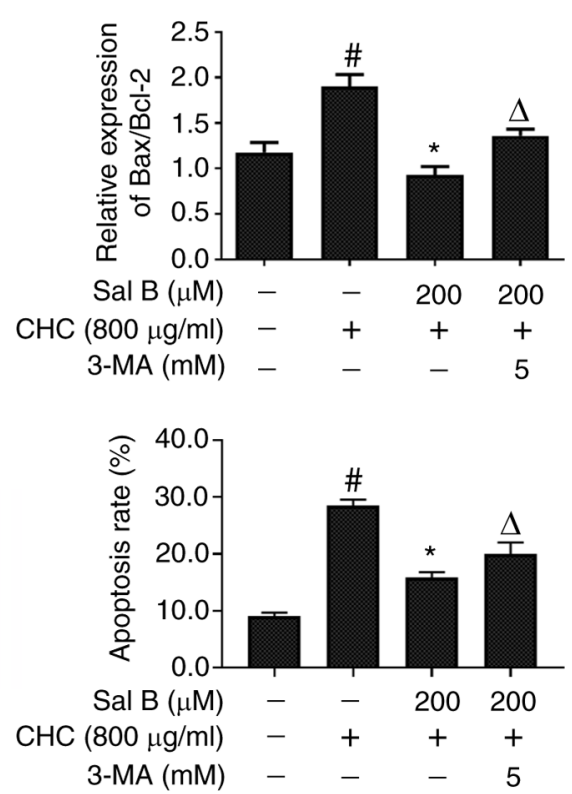

Figure 5. Sal B attenuates CHC-induced RAW264.7 macrophage apoptosis partially via improving autophagic dysfunction. The following groups are presented: CONT, untreated control; CHC, $800 \mu \mathrm{g} / \mathrm{ml} \mathrm{CHC} ; \mathrm{CHC}+\mathrm{Sal} \mathrm{B}, 800 \mu \mathrm{g} / \mathrm{ml} \mathrm{CHC}+200 \mu \mathrm{M} \mathrm{Sal} \mathrm{B}$; and CHC $+\mathrm{Sal} \mathrm{B}+3-\mathrm{MA}, 800 \mu \mathrm{g} / \mathrm{ml} \mathrm{CHC}+$ $200 \mu \mathrm{M}$ Sal B +5 mM 3-MA. Western blotting was performed to assess the expression of (A) autophagy- and (B) apoptosis-related proteins in CHC-induced RAW264.7 macrophages co-treated with Sal B and the autophagy inhibitor 3-MA $(n=3)$. (C) Annexin V-FITC/PI double staining was performed to determine the effect of Sal B and the autophagy inhibitor 3-MA on CHC-induced RAW264.7 macrophage apoptosis ( $\mathrm{n}=3$ ). ${ }^{\text {" }} \mathrm{P}<0.05$ vs. untreated control; ${ }^{*} \mathrm{P}<0.05 \mathrm{vs}$. $\mathrm{CHC} ;{ }^{\wedge} \mathrm{P}<0.05$ vs. CHC + Sal B. Sal B, salvianolic acid B; CHC, cholesterol crystal; 3-MA, 3-methyladenine.

apoptosis in macrophages, whereas suppressing autophagy could increase macrophage apoptosis, thus negatively regulating AS. The role of autophagy in apoptosis remains controversial. The present results indicated that Sal B significantly decreased macrophage apoptosis by improving autophagy. Macrophages were co-treated with Sal B and the autophagy inhibitor, 3-MA. The western blotting results suggested that 3-MA successfully attenuated the effect of Sal B on autophagy, partially compensating for the protective effect of Sal B on apoptosis. This finding indicated that the role of Sal B in reducing the apoptotic rate of RAW264.7 macrophages was partially due to its effect on relieving CHC-induced autophagy dysfunction.

Autophagy is regulated by a variety of signal transduction pathways. The adenylate-activated protein kinase/mTOR and $\mathrm{PI} 3 \mathrm{~K} / \mathrm{Akt} / \mathrm{mTOR}$ signaling pathways are two common cellular regulatory pathways of autophagy (38). The Akt/mTOR signal transduction pathway is closely associated with the occurrence of autophagy and regulation of apoptosis, and is considered as the only inhibitory signal transduction pathway regulating autophagy (39). Zhai et al (40) demonstrated that specifically inhibiting the Akt/mTOR signaling pathway notably 
A

Sal B $(\mu \mathrm{M}) \quad-\quad-100150200$

$\mathrm{CHC}(800 \mu \mathrm{g} / \mathrm{ml})-++++$

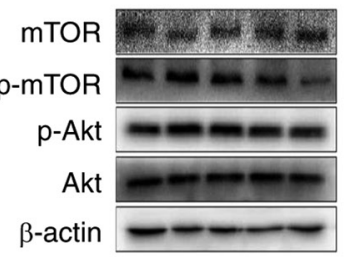

B

Sal B $(\mu \mathrm{M})--200200$

$\mathrm{CHC}(800 \mu \mathrm{g} / \mathrm{ml})-+++$

Insulin $(\mu \mathrm{g} / \mathrm{ml})--\quad 1$

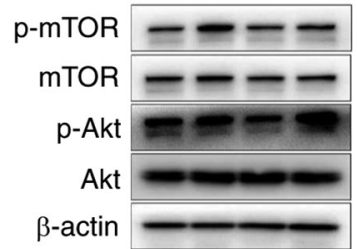

Sal B $(\mu \mathrm{M})-\quad-200200$

$\mathrm{CHC}(800 \mu \mathrm{g} / \mathrm{ml})-+++$

Insulin $(\mu \mathrm{g} / \mathrm{ml})-\quad-1$

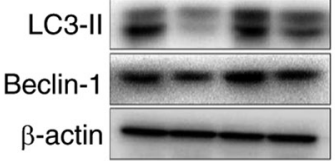

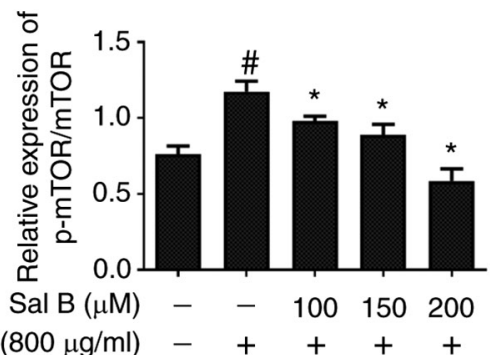

$\mathrm{CHC}(800 \mu \mathrm{g} / \mathrm{ml})-++++$

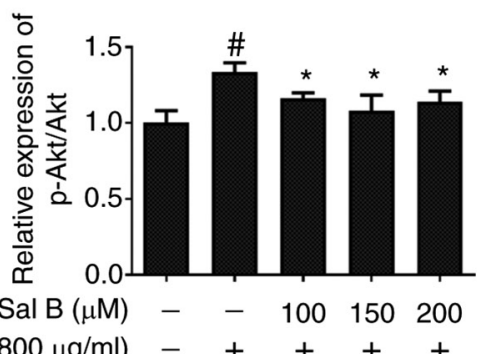

$\mathrm{CHC}(800 \mu \mathrm{g} / \mathrm{ml})-+++$
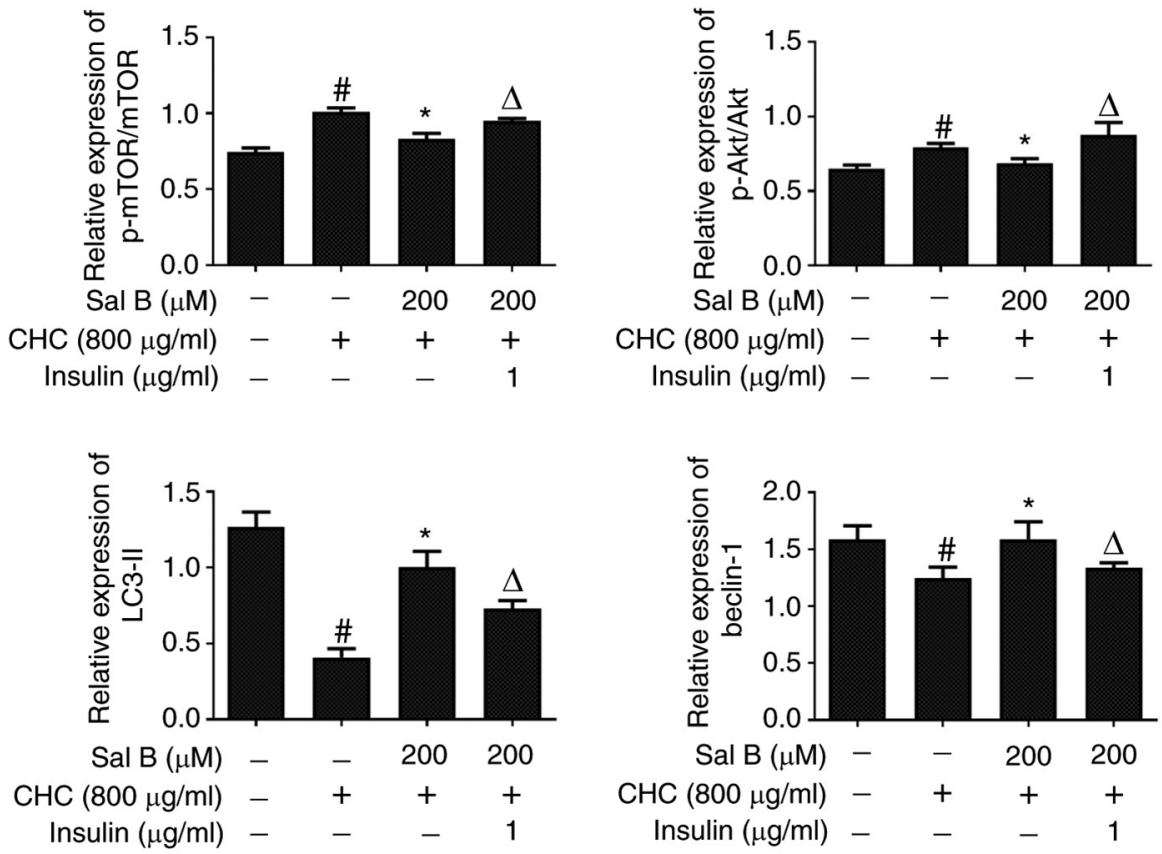

Figure 6. Sal B improves CHC-induced autophagic dysfunction in RAW264.7 macrophages partially via inhibiting the Akt/mTOR signaling pathway. (A) Western blotting was performed to assess the effect of Sal B on the expression of Akt/mTOR signaling pathway-related proteins in RAW264.7 macrophages $(\mathrm{n}=3)$. The following groups are presented: CONT, untreated control; $\mathrm{CHC}, 800 \mu \mathrm{g} / \mathrm{ml} \mathrm{CHC} ; \mathrm{CHC}+\mathrm{Sal} \mathrm{B} 100,800 \mu \mathrm{g} / \mathrm{ml} \mathrm{CHC}+100 \mu \mathrm{M} \mathrm{Sal} \mathrm{B} ; \mathrm{CHC}+$ Sal B 150,800 $\mu \mathrm{g} / \mathrm{ml} \mathrm{CHC}+150 \mu \mathrm{M}$ Sal B; and CHC + Sal B 200, $800 \mu \mathrm{g} / \mathrm{ml} \mathrm{CHC}+200 \mu \mathrm{M}$ Sal B. (B) Western blotting was performed to assess the effect of Sal B combined with insulin on the expression of Akt/mTOR signaling pathway- and autophagy-related proteins in CHC-induced RAW264.7 macrophages $(\mathrm{n}=3)$. The following groups are presented: CONT, untreated control; $\mathrm{CHC}, 800 \mu \mathrm{g} / \mathrm{ml} \mathrm{CHC} ; \mathrm{CHC}+\mathrm{Sal} \mathrm{B}, 800 \mu \mathrm{g} / \mathrm{ml} \mathrm{CHC}+200 \mu \mathrm{M} \mathrm{Sal} \mathrm{B}$; and CHC + Sal B + insulin, $800 \mu \mathrm{g} / \mathrm{ml} \mathrm{CHC}+200 \mu \mathrm{M}$ Sal B $+1 \mu \mathrm{g} / \mathrm{ml}$ insulin. ${ }^{\# \mathrm{P}}<0.05$ vs. untreated control; ${ }^{*} \mathrm{P}<0.05 \mathrm{vs}$. CHC; ${ }^{\Delta} \mathrm{P}<0.05 \mathrm{vs}$. CHC $+\mathrm{Sal} \mathrm{B}$. Sal B, salvianolic acid B; CHC, cholesterol crystal; p, phosphorylated.

enhanced macrophage autophagy, eventually attenuating the infiltration of macrophages and enhancing the stability of the atherosclerotic plaque. To investigate the molecular mechanism underlying the effect of Sal B on improving autophagy function, macrophages were treated with Sal B and insulin, an agonist of the Akt/mTOR signaling pathway. Insulin inhibited Sal B-mediated inactivation of Akt/mTOR signaling in CHC-induced macrophages, which partially restored Sal B-induced autophagy. The results of the present study suggested that CHCs induced autophagy dysfunction in macrophages via activating the Akt/mTOR signaling pathway, whereas Sal B partially improved autophagy dysfunction in RAW264.7 macrophages via blocking the Akt/mTOR signaling pathway.

In summary, the results of the present study revealed that Sal B partially improved RAW264.7 macrophage autophagy dysfunction via inhibiting the Akt/mTOR signaling pathway to attenuate macrophage apoptosis. In addition, treatment of macrophages with Sal B inhibited CHC-induced release of proinflammatory cytokines (TNF- $\alpha$ and IL-6). Overall, the present study may provide novel insight into the molecular mechanism underlying the beneficial effects of Sal B on AS.

\section{Acknowledgements}

Not applicable.

\section{Funding}

The present study was supported by the Technology Bureau of Luzhou city (grant nos. 2015LZCYD-S03 and 2020LZXNYDJ18), the Department of Science and Technology of the Sichuan Province (grant no. 17YYJC0441).

\section{Availability of data and materials}

The datasets used and/or analyzed during the current study are available from the corresponding author on reasonable request. 


\section{Authors' contributions}

MS, SW and YH contributed to designing the study. MS, WY and ZY performed the experiments. YY analyzed the data. MS, YY and YH drafted the manuscript. All authors read and approved the final manuscript. MS and SW confirm the authenticity of all the raw data.

\section{Ethics approval and consent to participate}

Not applicable.

\section{Patient consent for participation}

Not applicable.

\section{Competing interests}

The authors declare that they have no competing interests.

\section{References}

1. Lusis AJ: Atherosclerosis. Nature 407: 233-241, 2000.

2. Hansson GK: Mechanisms of disease: Inflammation, atherosclerosis, and coronary artery disease. N Engl J Med 352: 1685-95, 2005.

3. Schrijvers DM, De Meyer GR, Herman AG and Martinet W: Phagocytosis in atherosclerosis: Molecular mechanisms and implications for plaque progression and stability. Cardiovasc Res 73: 470-480, 2007

4. Shao BZ, Han BZ, Zeng YX, Su DF and Liu C: The roles of macrophage autophagy in atherosclerosis. Acta Pharmacol Sin 37: 150-156, 2016.

5. Mizushima N and Komatsu M: Autophagy: Renovation of cells and tissues. Cell 147: 728-741, 2011.

6. Yorimitsu T and Klionsky DJ: Autophagy: Molecular machinery for self-eating. Cell Death Differ 12 (Suppl 2): S1542-S1552, 2005.

7. Levine B and Kroemer G: Autophagy in the pathogenesis of disease. Cell 132: 27-42, 2008.

8. Liao XH, Sluimer JC, Wang Y, Subramanian M, Brown K, Pattison JS, Robbins J, Martinez J and Tabas I: Macrophage autophagy plays a protective role in advanced atherosclerosis. Cell Metab 15: 545-553, 2012

9. Grootaert MOJ, Lynn R, Schrijvers DM, De Meyer GRY and Martinet W: Defective autophagy in atherosclerosis: To die or to senesce? Oxid Med Cell Longev 2018: 7687083, 2018.

10. Dong Y, Chen H, Gao J, Liu Y,Li J and Wang J: Molecular machinery and interplay of apoptosis and autophagy in coronary heart disease. J Mol Cell Cardiol 136: 27-41, 2019.

11. Wang K: Autophagy and apoptosis in liver injury. Cell Cycle 14: 1631-1642, 2015 .

12. Cheng TO: Cardiovascular effects of Danshen. Int J Cardiol 121: 9-22, 2007.

13. Xue L, Wu Z, Ji XP, Gao XQ and Guo YH: Effect and mechanism of salvianolic acid $\mathrm{B}$ on the myocardial ischemia-reperfusion injury in rats. Asian Pac J Trop Med 7: 280-284, 2014.

14. Lee HJ, Seo M and Lee EJ: Salvianolic acid B inhibits atherogenesis of vascular cells through induction of Nrf2-dependent heme oxygenase-1. Curr Med Chem 21: 3095-3106, 2014.

15. Han X, Liu JX and Li XZ: Salvianolic acid B inhibits autophagy and protects starving cardiac myocytes. Acta Pharmacol Sin 32: 38-44, 2011.

16. Wu YT, Tan HL, Shui G, Bauvy C, Huang Q, Wenk MR, Ong CN, Codogno P and Shen HM: Dual role of 3-methyladenine in modulation of autophagy via different temporal patterns of inhibition on class I and III phosphoinositide 3-kinase. Biol Chem 2: 10850-10861, 2010.

17. Heras-Sandoval D, Pérez-Rojas JM, Hernández-Damián J and Pedraza-Chaverri J: The role of PI3K/AKT/mTOR pathway in the modulation of autophagy and the clearance of protein aggregates in neurodegeneration. Cell Signal 26: 2694-2701, 2014.

18. Kojima Y, Weissman IL and Leeper NJ: The role of efferocytosis in atherosclerosis. Circulation 135: 476-489, 2017.
19. Linton MRF, Babaev VR, Huang J,Linton EF, Tao H and Yancey PG: Macrophage apoptosis and efferocytosis in the pathogenesis of atherosclerosis. Circ J 80: 2259-2268, 2016.

20. Poon IKH, Lucas CD, Rossi AG and Ravichandran KS: Apoptotic cell clearance: Basic biology and therapeutic potential. Nat Rev Immunol 14: 166-180, 2014.

21. Manabu K, Linbo L, Chu KK, Sun CH, Tanaka A, Gardecki JA and Tearney GJ: Feasibility of the assessment of cholesterol crystals in human macrophages using micro optical coherence tomography. PLoS One 9: e102669, 2014.

22. Whiting MJ and Watts JM: Cholesterol crystal formation and growth in model bile solutions. J Lipid Res 24: 861-868, 1983.

23. Duewell P, Kono H, Rayner KJ, Sirois CM, Vladimer G, Bauernfeind FG, Abela GS, Franchi L, Nuñez G, Schnurr M, et al: NLRP3 inflammasomes are required for atherogenesis and activated by cholesterol crystals. Nature 466: 652-652, 2010.

24. Rajamäki K, Lappalainen J, Öörni K, Välimäki E, Matikainen S, Kovanen PT and Eklund KK: Cholesterol crystals activate the NLRP3 inflammasome in human monocytes and macrophages. Chem Physics of Lipids 163 (Suppl): S27-S28, 2010.

25. Zhou L, Jia Y and Li XH: LXR $\alpha$ agonist inhibits activation of macrophage NLRP3 inflammatory corpuscles through NF- $\kappa \mathrm{B}$ pathway leading to increased mature IL-1 $\beta$. Chin J Arterioscler 23: 17-23, 2015 (In Chinese).

26. Sergin I, Bhattacharya S, Emanuel R, Esen E, Stokes CJ, Evans TD, Arif B, Curci JA and Razani B: Inclusion bodies enriched for p62 and polyubiquitinated proteins in macrophages protect against atherosclerosis. Sci Signal 9: ra2, 2016.

27. Singh R, Kaushik S, Wang Y, Xiang Y, Novak I, Komatsu M, Tanaka K, Cuervo AM and Czaja MJ: Autophagy regulates lipid metabolism. Nature 458: 1131-1135, 2009.

28. Li ZM, Xu SW and Liu PQ: Salvia miltiorrhizaBurge (Danshen): A golden herbal medicine in cardiovascular therapeutics. Acta Pharmacol Sin 39: 802-824, 2018.

29. Wang SL, Lin Y and Tang ZY: Progress on research of salviae and salvianolic acid B in treating myocardial infarction with myocardial cell orientating differentiation of bone marrow mesenchymal stem cell. Zhongguo Zhong Xi Yi Jie He Za Zhi 30: 1334-1337, 2010 (In Chinese).

30. Wang L, Jiang H, Yang F, Du Y, Jia X, Si S and Hong B: Role of salvianolic acid B in cholesterol efflux of macrophages. China Medical Biotechnology 8: 100-106, 2013 (In Chinese).

31. Gao F, Sun GB, Ren X, Nie Y, Sun J, Qin M and Sun X: Protective effect of salvianolic acid B on isolated heart ischemia/reperfusion injury in rats. Zhongguo Zhong Yao Za Zhi 37: 358-361, 2012 (In Chinese).

32. Jing Z, Fei W, Zhou J, Zhang L, Chen L, Zhang X, Liang X, Xie J, Fang Y, Sui X, et al: Salvianolic acid B, a novel autophagy inducer, exerts antitumor activity as a single agent in colorectal cancer cells. Oncotarget 7: 61509-61519, 2016.

33. Furuya D, Tsuji N, Yagihashi A and Watanabe N: Beclin 1 augmented cis-diamminedichloroplatinum induced apoptosis via enhancing caspase-9 activity. Exp Cell Res 307: 26-40, 2005.

34. Yee KS, Wilkinson S, James J, Ryan KM and Vousden KH: PUMAand Bax-induced autophagy contributes to apoptosis. Cell Death Differ 16: 1135-1145, 2009.

35. Shang Y and Xian Lu: Relationship between apoptosis and autophagy during tumor treatment. Advances in Modern Biomedicine 10: 766-769, 2010 (In Chinese).

36. Mariño G, Niso-Santano M, Baehrecke EH and Kroemer G: Self-consumption: The interplay of autophagy and apoptosis. Nat Rev Mol Cell Biol 15: 81-94, 2014

37. Wang Q, Zeng P, Liu Y, Wen G, Fu X and Sun X: Inhibition of autophagy ameliorates atherogenic inflammation by augmenting apigenin-induced macrophage apoptosis. Int Immunopharmacol 27: 24-31, 2015.

38. Jung CH, Ro SH, Cao J, Otto NM and Kim DH: mTOR regulation of autophagy. FEBS Lett 584: 1287-1295, 2010.

39. Chang Z, Shi G, Jin J, Guo H, Guo X, Luo F, Song Y and Jia X: Dual PI3K/mTOR inhibitor NVP-BEZ235-induced apoptosis of hepatocellular carcinoma cell lines is enhanced by inhibitors of autophagy. Int J Mol Med 31: 1449-1456, 2013.

40. Zhai CG, Cheng J, Mujahid H, Wang H, Kong J, Yin Y, Li J,Zhang Y, Ji X and Chen W: Selective inhibition of Akt/mTOR signaling pathway regulates autophagy of macrophage and vulnerability of atherosclerotic plaque. PLoS One 9: e90563, 2014.

This work is licensed under a Creative Commons Attribution-NonCommercial-NoDerivatives 4.0 International (CC BY-NC-ND 4.0) License. 